\title{
Development of a Quenching-Partitioning Process Chain for Forging Components
}

\section{Marcel Graf ${ }^{1, a^{*}}$, Sebastian Härtel ${ }^{1, b}$, Alexander Bauer ${ }^{1, \mathrm{c}}$, Wolfgang Förster ${ }^{1, \mathrm{~d}}$, Dagmar Bublikova $^{3, \mathrm{e}}$, Martin F.-X. Wagner ${ }^{2, \mathrm{f}}$, Birgit Awiszus ${ }^{1, g}$, Bohuslav Masek ${ }^{4, h}$}

\author{
${ }^{1}$ TU Chemnitz, Professorship Virtual Production Engineering, Chemnitz, Germany \\ ${ }^{2}$ TU Chemnitz, Professorship of Materials Engineering, Chemnitz, Germany \\ ${ }^{3}$ University of West Bohemia, RTI, Pilsen, Czech Republic \\ ${ }^{4}$ COMTES FHT, Dobrany, Czech Republic \\ amarcel.graf@mb.tu-chemnitz.de, bsebastian.haertel@mb.tu-chemnitz.de, \\ calexander.bauer@mb.tu-chemnitz.de, 'wolfgang.foerster@mb.tu-chemnitz.de, \\ edagmar.bublikova@rti.zcu.cz, ${ }^{\mathrm{f}}$ martin.wagner@mb.tu-chemnitz.de, \\ 9birgit.awiszus@mb.tu-chemnitz.de, hbmasek@comtesfht.com
}

Keywords: QP process, bulk forming, numerical simulation, cooling behaviour, modelling

\begin{abstract}
The aim is to realize a Q\&P (Quenching and Partitioning) process for a hot forged component made of low-alloyed advanced high-strength steel (AHSS) 42MnSiCr. One advantage of this steel is the low alloy concept which is cost-effective. After forging, the component is cooled down to room temperature with a subsequent heat treatment to achieve the characteristic microstructure with martensite and retained austenite. The material is annealed and then quenched to just above the martensite finish temperature $\left(\mathrm{M}_{\mathrm{F}}\right.$-temperature). Hence, in the martensitic matrix about 10 to $15 \%$ retained austenite is included. Finally, the Q\&Ped material is artificially aged at $250{ }^{\circ} \mathrm{C}$ to support the diffusion process of carbon from the over-saturated martensite into the austenite. Thereby, mechanical properties of $2000 \mathrm{MPa}$ for tensile strength with fracture strains of $10 \%$ can be achieved. This paper provides details of the process and material behavior for a reduction of the process chain. The goal is to develop a technology for the quenching and partitioning treatment of forged components by using the thermal energy from forging. Ideally, the quenching step should be performed in the forming dies just above the $\mathrm{M}_{\mathrm{F}}$-temperature with additional holding on the temperature level. The majority of forged parts have different cross sections. Therefore, the cooling conditions are inhomogeneous in each cross section of the components. This cooling behavior was analyzed in laboratory tests with a forged part. Furthermore, the heat transfer coefficients were determined for different cooling media (water, air). The cooling technology was experimentally and numerically simulated in a first step for the conventional process chain (forging, cooling to room temperature, austenitisation, quenching, artificial ageing) and correlated with the microstructural evolution in combination with the component's mechanical properties.
\end{abstract}

\section{Introduction}

In the last decades, lightweight design has become important in daily life. The global aim in this context is the reduction of greenhouse gases, in particular $\mathrm{CO}_{2}$, during the production process and the application of the products. One possibility is the material substitution by using light alloys or the utilization of high strength steels. In the last years, new technologies for conventional steel alloys or new alloy systems have been developed that contribute to this global aim. A focus is set on the higher strength with sufficient ductility at the same time in comparison to conventional steel grades, which allows for a thinner and thus lighter component design. 
Different alloying concepts were developed for the Q\&P process from low alloy steel grades [1][7] to stainless steels [8]. The main alloying elements are $\mathrm{Mn}, \mathrm{Si}$ and sometimes $\mathrm{Cr}$ and $\mathrm{Ni}$. A typical process route is shown schematically in Figure 1, and is marked by quenching and partitioning. The first sub-step of this heat treatment is quenching from the austenitisation temperature $\left(900-950^{\circ} \mathrm{C}\right)$ to an alloy-dependent quenching temperature $(\mathrm{QT})$ above the $\mathrm{M}_{\mathrm{F}}$ temperature $\left(-40-300^{\circ} \mathrm{C}\right)$. In addition to the martensite in the matrix, a well-defined volume fraction of retained austenite must be precisely adjusted, and is also a result of the chemical composition. The cooling rate and QT depend on the necessary amount of retained austenite and on the nominal carbon content [4], [6]. During the following partitioning, carbon diffuses from the martensitic needles into the retained austenite. The partitioning temperature (PT) is set in the range of QT $\left(180-400{ }^{\circ} \mathrm{C}\right.$ and $-130^{\circ} \mathrm{C}$ [8]), either in a one-step-process (i.e., PT is equal to QT) or in a two-step-process (PT is higher than QT) [7]. The various artificial ageing strategies and the holding time significantly influence the mechanical properties because the underlying microstructural changes occur by diffusion-controlled processes [2], [3].

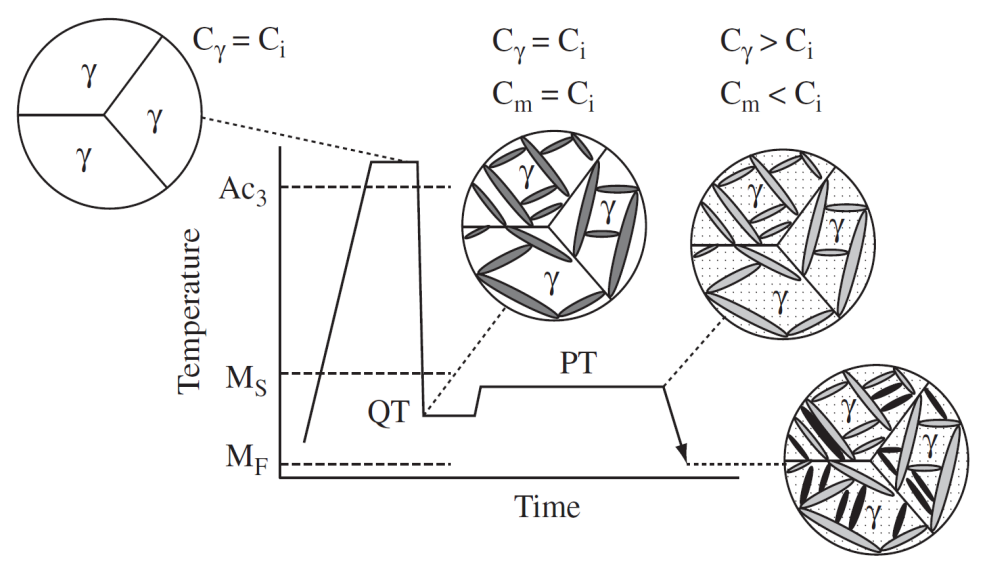

Fig. 1. General time temperature regime for $\mathrm{Q} \& \mathrm{P}$ processes as a two-step process $\left(\mathrm{C}_{\mathrm{i}}=\right.$ carbon content initial state; $\mathrm{C}_{\gamma}=$ carbon content in austenite; $\mathrm{C}_{\mathrm{m}}=$ carbon content in martensite) [5]

If partitioning is performed at QT, the tensile strength increases in comparison to the two-step strategy. Otherwise the ductility tends to higher values at a higher PT [7].

\section{Experimental Setup}

Material. For the experimental investigations, a forged workpiece was used to conduct a final heat treatment process to reach Q\&P steel qualities at the end of the process line. This kind of special heat treatment requires a defined chemical composition to ensure that the mechanical properties needed (high strength combined with ductility) can evolve from the heat treatment. The material used for the experimental investigations was an AHS steel with the chemical composition summarized in table 1. The chemical composition was determined by the SPECTROMAXx metal analyzer in combination with the optical emission spectrometry (OES).

Table 1. Chemical composition of the AHS steel

\begin{tabular}{|c|c|c|c|c|c|c|c|c|c|c|c|}
\hline $\mathrm{C}$ & $\mathrm{Si}$ & $\mathrm{Mn}$ & $\mathrm{P}$ & $\mathrm{S}$ & $\mathrm{Cr}$ & $\mathrm{Mo}$ & $\mathrm{Ni}$ & $\mathrm{Al}$ & $\mathrm{Cu}$ & $\mathrm{Nb}$ & $\mathrm{Ti}$ \\
\hline 0.42 & 2.09 & 2.45 & 0.005 & 0.002 & 1.34 & 0.04 & 0.56 & 0.005 & 0.06 & 0.03 & 0.0151 \\
\hline
\end{tabular}

The component used in the present study is the product of a complex closed die forging process with three process steps, as shown in Figure 2 (left). For the heat treatment processes, the component was cut in half, as shown in Figure 2 (right). The forging process itself is of minor importance for this study: Due to the Q\&P characteristics, the microstructure, transforms during a separate heat treatment process within these experiments. 


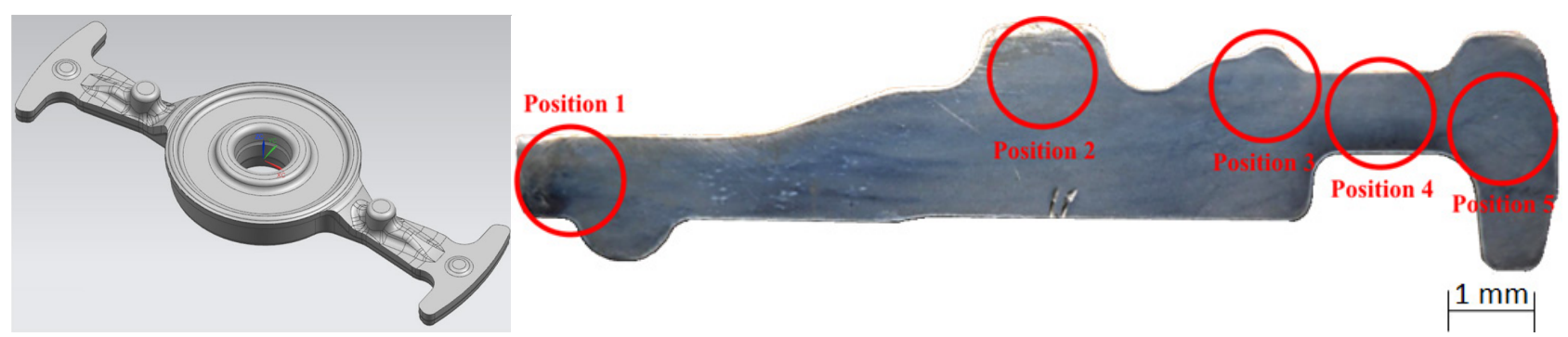

Fig. 2. Left: Complete forged component $\mathrm{CAD}^{1}$; right: Cross section of heat-treated half of the component (positions for microstructural and mechanical investigations are highlighted)

Heat treatment. The annealing experiments were performed in a radiation and a circulating air furnace. Two different routes were selected to adjust different morphologies of martensite (fast cooling strategy for fine martensitic structure; slower cooling strategy for coarse martensitic needles). The water cooling strategy reduces only the temperature near the surface very quickly but not within the component (short quenching time). After quenching in water, the component was removed out of the water bath and reheating occurred due to the remaining heat of the core. The partitioning near the surface therefore corresponds to a two-step process whereas in the core a single step Q\&P process with lower cooling rates occurs. To examine how the different heat treatments influence the $\mathrm{Q} \& \mathrm{P}$ results, they were compared to each other with a focus on the different martensite morphologies. The routes are defined as route 1 "water cooling" and route 2 "furnace cooling" (Figure 3).
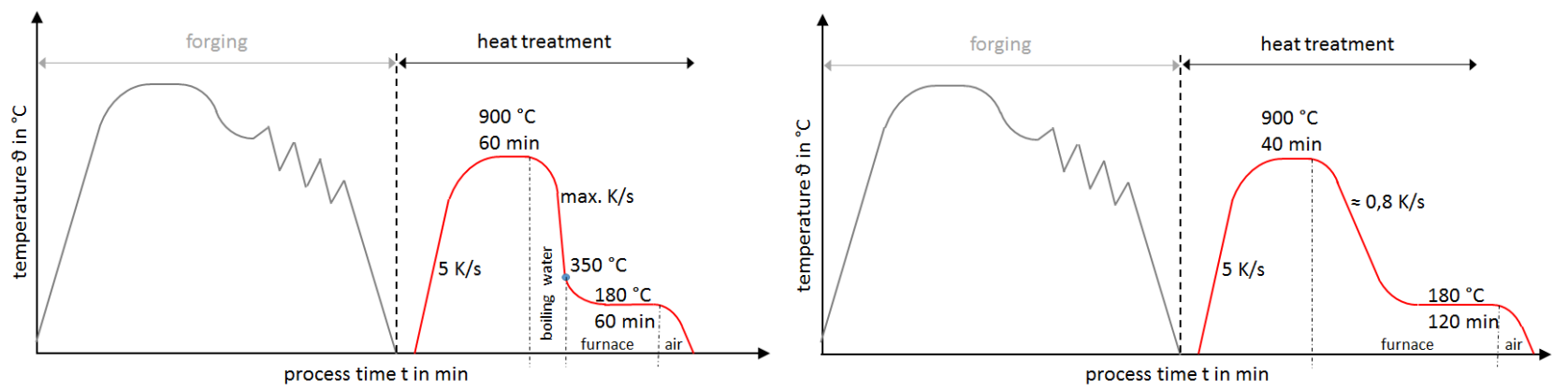

Fig. 3. Routes for Q\&P with different cooling strategies (left: route 1 with quenching in water up to $350{ }^{\circ} \mathrm{C}$; right: route 2 with component cooling in a furnace with $180^{\circ} \mathrm{C}$ )

For the validation of the experimental heat treatment processes, three thermocouples type $\mathrm{K}$ (NiCr-Ni thermocouple) were positioned on the specimen. Holes were drilled into the specimen to measure the temperature at different positions in varying depths ( $\vartheta 1$ near surface, $\$ 2$ and $\$ 310 \mathrm{~mm}$ below the surface on position 2 and 3 ). The positions were chosen at locations where a variation of the cooling rate was expected.

After preparing the specimen, the heat treatment was performed as described above. A chamber furnace was used to heat the specimen up to $900{ }^{\circ} \mathrm{C}$ and, if defined by the processing route, the second heat treatment at $180^{\circ} \mathrm{C}$ (partitioning) was performed in a convection furnace. Between these process steps, the specimen was cooled in boiling water (route 1) or in warm air/furnace (route 2). The final cooling in air was performed for all heat treatment routes. For measurements of the temperature during the heat treatment process, an ALMEMO 2890-9 data logger was applied with the associated software.

Material characterization. For the correlation between temperature development and microstructural evolution, microstructures were primarily investigated near the positions of the thermocouples. Low-magnification macrostructure views show the material flow corresponding to the production process. The structure is homogeneous and without internal defects. There is no grain roughness in the edge regions or inside the forgings. The average grain size is approximately $30 \mu \mathrm{m}$ after forging and prior to austenitisation.

\footnotetext{
${ }^{1}$ Prof. Uwe Mahn, University of Applied Sciences Mittweida
} 


\section{Numerical Setup}

Numerical modelling of the heat treatment was performed within the FEM software Simufact.forming 14.0. This program was used for the simulation of the temperature development within the specimen. Furthermore, a calibrated numerical simulation allows for convenient parameter variations (e.g. holding times) within the heat treatment processes. This leads to information about an optimal duration and route of the heat treatment for different component geometries. Additionally, it improves the accuracy of the results with respect to the material's properties and microstructure. Consequently, the model was set up as a heat treatment simulation. The component was modeled with a symmetry plane to save computational time. The material was taken from the Simufact database (DB.42CrMo4). Note that the material data were of minor importance because the focus was simply on the temperature development, controlled by the heat transfer and emission coefficients. These coefficients were adjusted within every single treatment step, to gain a good accordance between the simulated and experimental temperature curves. As described below, the specimen was meshed with tetrahedral elements (Tet157) with an average size of $3.3 \mathrm{~mm}$ and a total amount of 121.000 elements. The time step was set to automatic and the fragmentation of the results was adapted for the different process steps (heating, cooling in water etc.). A domain decomposition was used with a four-core parallelization.

\section{Results}

Experimental investigations. The temperatures during the different heat treatments were measured and some special characteristics can be observed for each route at the cooling process. Especially, the cooling in boiling water shows a significant change of the cooling rate, which can be seen between $3585 \mathrm{~s}$ and $4150 \mathrm{~s}$ in Figure 4.

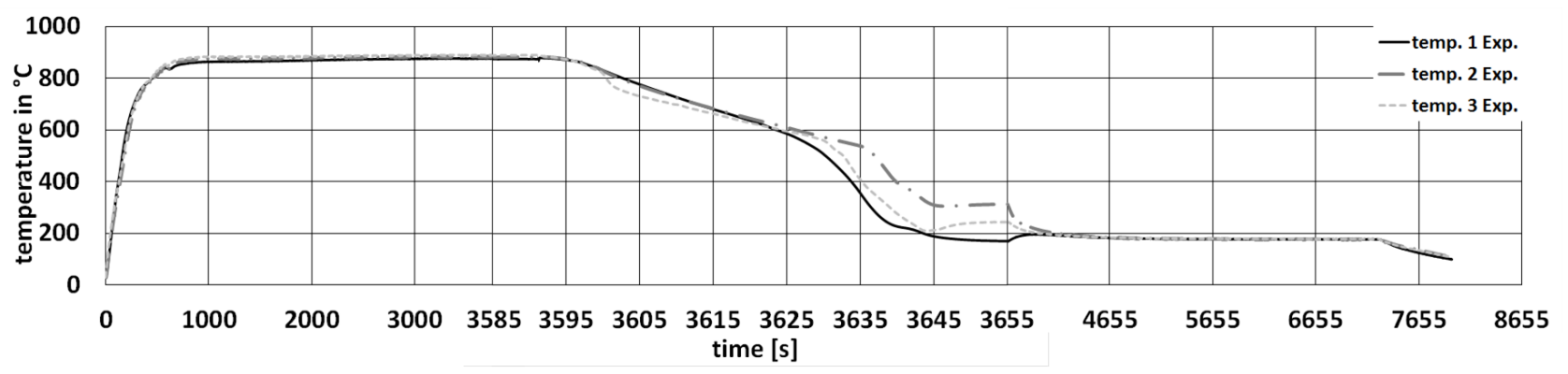

Fig. 4. Measured temperature development of heat treatment route 1

In contrast to the fast cooling rate within water (Figure $5-$ left), the cooling within the furnace (Figure 5 - right) leads to a smoother decrease of the temperature which is directly connected to the microstructure evolution in the specimen. Additionally, the thermocouples show different temperatures due to the variating positions and depths within the specimen. With the measured temperatures, it is possible to correlate the resulting microstructures and the corresponding temperatures during the heat treatment as discussed in the chapter microstructure evolution.
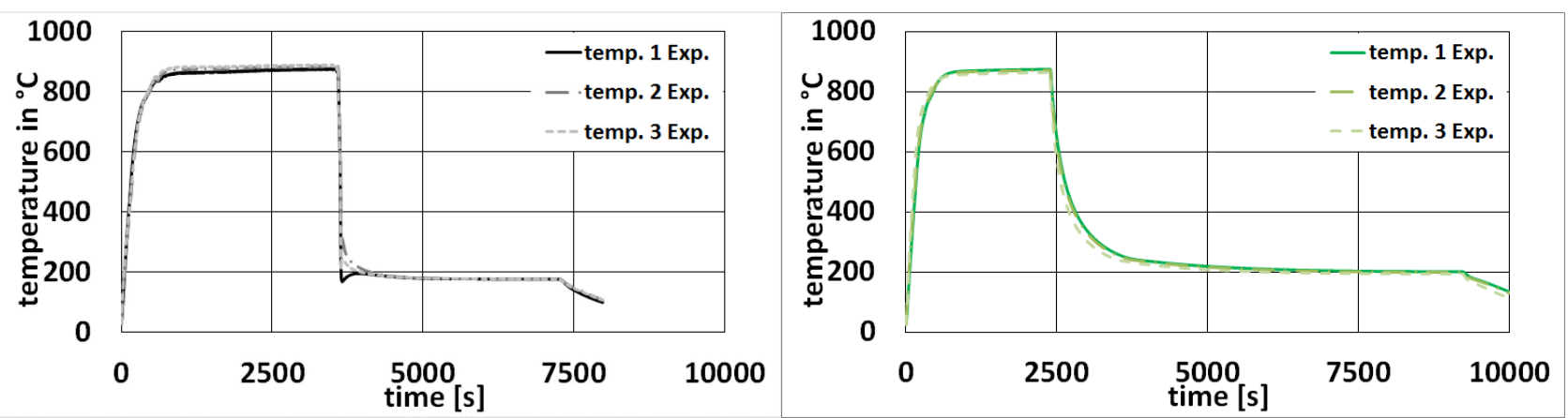

Fig. 5. Measured temperatures for process route 1 (left) and process route 2 (right) 
Numerical simulation. The numerical simulation was performed to model the different temperatures within the specimen, with respect to different cooling methods. Within the setup of process route 1, all of these different cooling (and heating) environments are included. Therefore, this process route was used to calibrate the numerical simulation with the experimental data. The most challenging part was the reproduction of the cooling in boiling water. During the water cooling, a significant change of the cooling rate can be detected in the temperature development as already seen from the experimental results (Figure 4). This determinations correlate with some numerical investigations of the cooling effect of single water drops or the phenomena of film vapour or stabile vapour cooling with water spray systems [9], [10]. Considering this observation, an adjustment of the heat transfer coefficient needs to be made to achieve a good agreement between experiment and FEM. This coefficient was implemented as table curve, which consider the heat transfer coefficient over the temperature (shown in Figure 6).

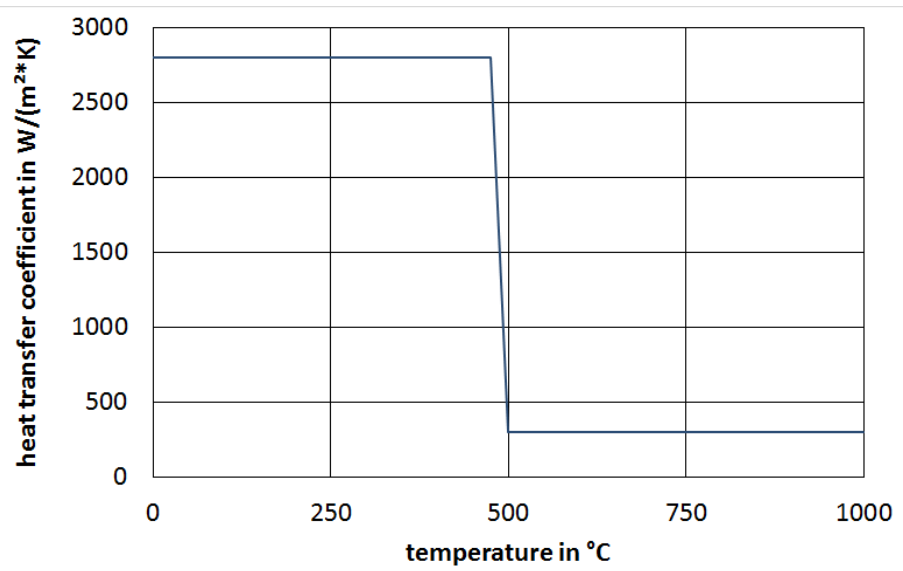

Fig. 6. Heat transfer coefficient as a function of temperature, adapted for the simulation of water cooling

For the FEM simulation of the heating and cooling behavior in the furnace and in air, constant heat transfer coefficients were considered: heating in furnace $\left(900^{\circ} \mathrm{C}\right): \alpha=50 \mathrm{~W} /\left(\mathrm{m}^{2 *} \mathrm{~K}\right)$; cooling in furnace $\left(180{ }^{\circ} \mathrm{C}\right): \alpha=25 \mathrm{~W} /\left(\mathrm{m}^{2 *} \mathrm{~K}\right)$; cooling in air: $\alpha=10 \mathrm{~W} /\left(\mathrm{m}^{2 *} \mathrm{~K}\right)$. The differences between the heat transfer coefficients of heating and cooling in the furnace may be caused by different thermal radiation and by changes of the surface structure (scale) of the specimen as there was no shielding gas used in the furnace during the conducted experiments. These effects can lead to different conditions on the surface of the specimen. With the use of these different heat transfer coefficients in the numerical simulation, a good agreement was achieved with the experimental data, as it can be seen in Figure 7.
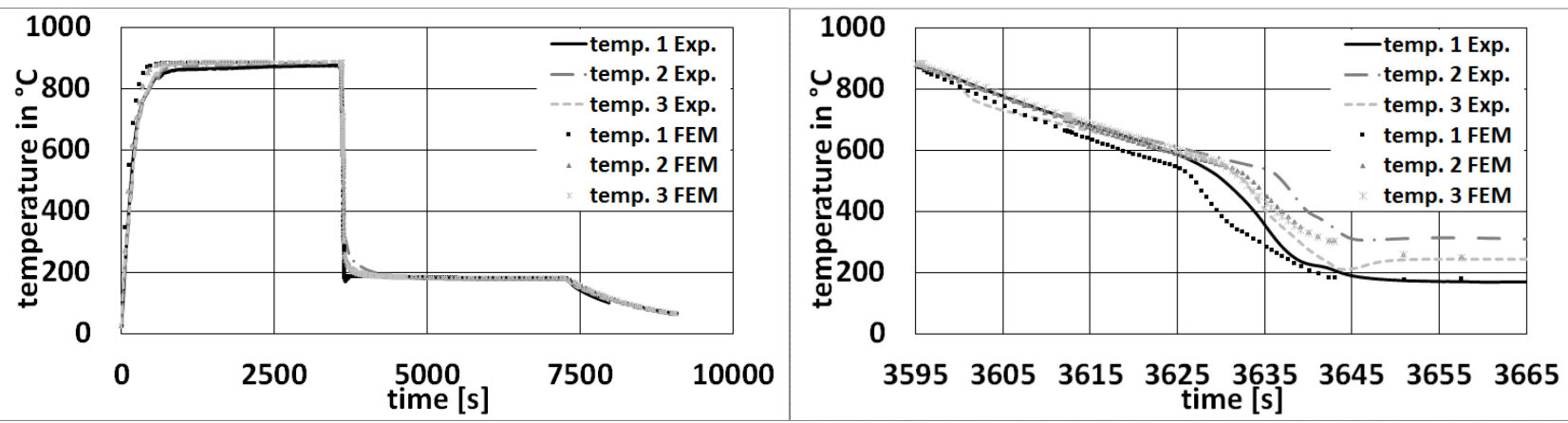

Fig. 7. Measured and simulated temperatures for entire heat treatment (left) and for cooling process (right) of route 1

Figure 7 shows that some variations remain between the data from the thermocouples and the evaluated points in the FEA. These differences may result from the sensitivity of the thermocouples in the real process which causes fluctuations between the measurement points. This effect is not that intense within the numerical simulation. Due to the very fast cooling and the complex 
thermodynamic phenomena the FEM, with the simplifications made, achieves a good agreement with the experimentally measured temperature flow. The most important information from the numerical simulation is that the surface of the specimen was reheated after the quenching process within water because of the remaining heat from the inside. In comparison, the core shows a smoother cooling rate. The difference between these cooling rates inside and at the surface of the specimen leads to different martensite structures as well. The successful verification of the FEM shows that the prediction of the cooling or heating of a workpiece is possible in various environments and process routes. Therefore, another calibration was done for heat treatment route 2 (Figure 8), which also shows a good agreement between FEA and experiment. This strategy was selected with the aim of a gradual cooling rate and hence a different development of the martensitic microstructure.

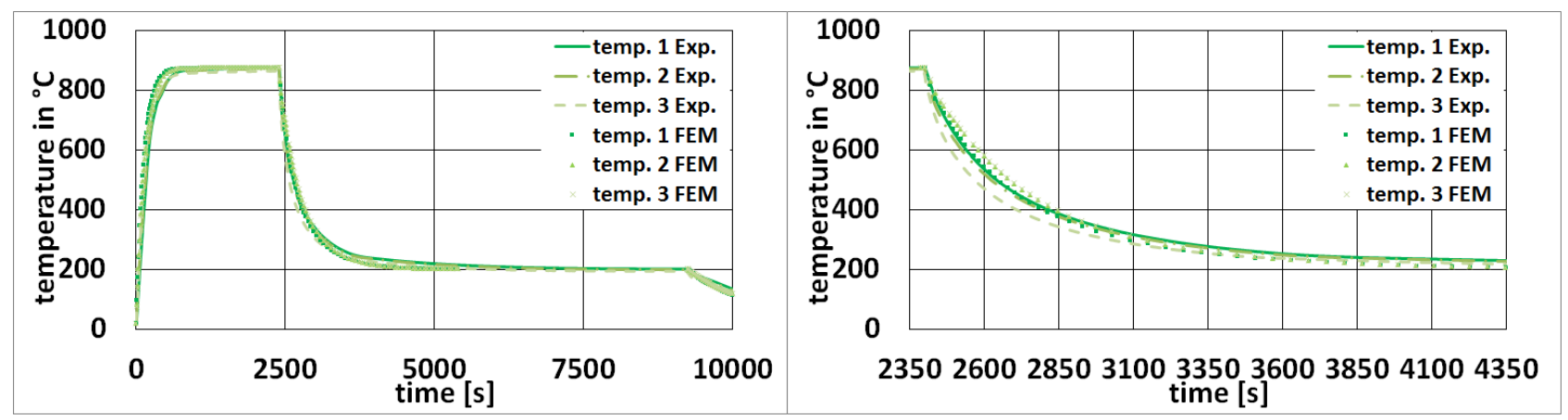

Fig. 8. Measured and simulated temperatures for entire heat treatment (left) and cooling process (right) of route 2

The results presented here show that the temperature development of various workpieces with differing cooling strategies can be simulated in advance and such simulations can be used to predict which part of the workpiece is subjected to different thermal histories. According to the temperature development and with the help of the chemical composition and the corresponding material properties, the microstructural evolution can also be predicted qualitatively, as it is in principle known how cooling rate influences a microstructural development and the associated phase transformation. Clearly, with the help of this approach to cooling simulation, useful statements can be made to predict the prospects for successful heat treatment methods.

Microstructural evolution and mechanical properties. After the experimental Q\&P treatments, a predominantly martensitic matrix with a volume fraction of about $10 \%$ of retained austenite was obtained. A finer martensite was developed by the use of cooling strategy 1 (see also Figure 9). In contrast, the martensitic needles are enlarged after cooling within the furnace (cooling strategy 2), while the amount of austenite remains almost the same (Figure 9 from top to bottom). Thus, the required cooling rates for the development of a characteristic Q\&P-microstructure were achieved for both strategies. The same can be observed along the radial axis (from left to right): In contrast to position 5, a finer martensite is observed at position 1, which can be rationalized by the generally faster cooling rate at this position. 


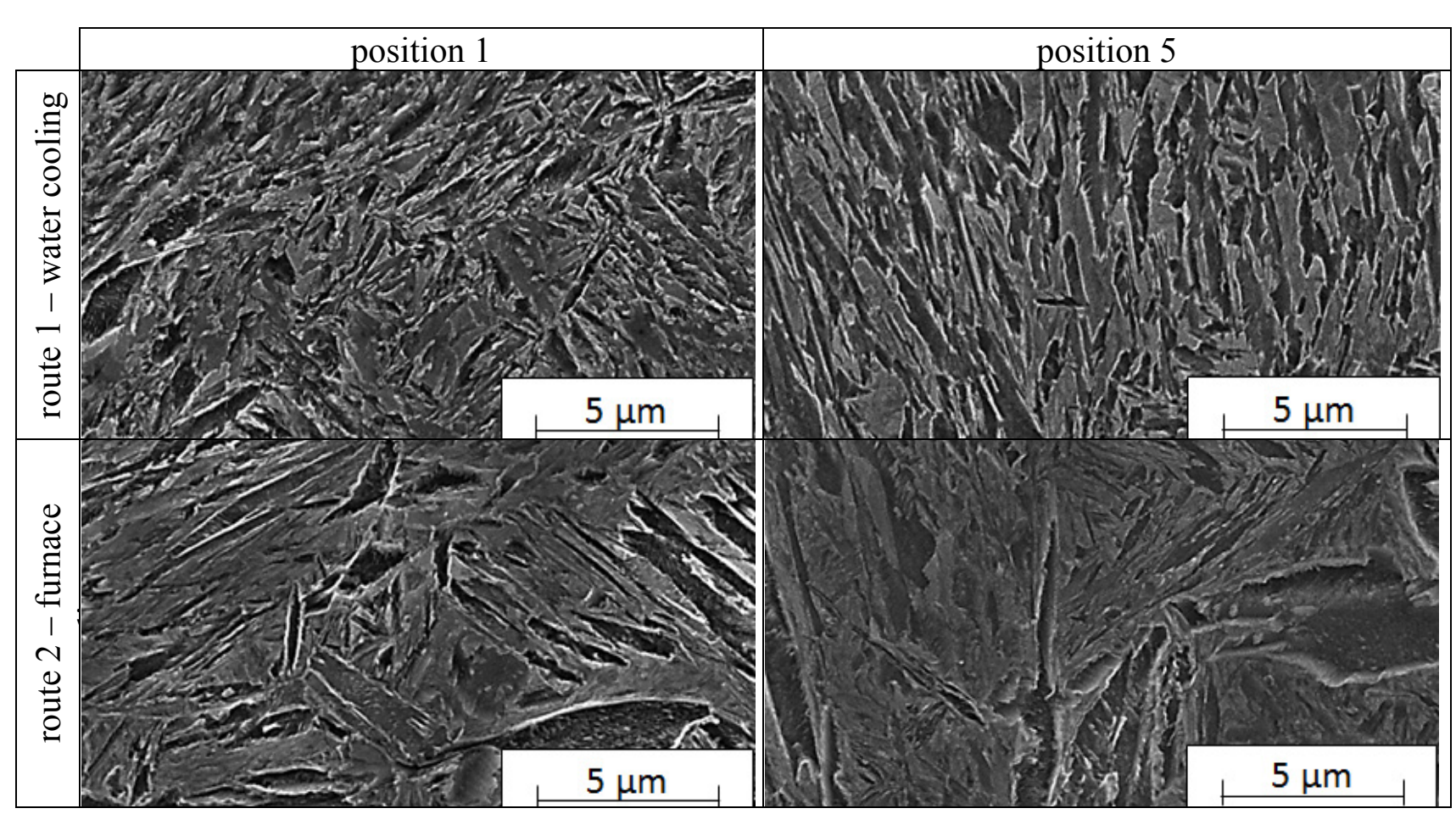

Fig. 9. Scanning electron micrographs of the microstructures for the two routes and at two positions

Table 2 shows the average values of the Vickers hardness (HV10) at different positions on the cross section of the component (Figure 2) for the described routes. Depending on the position within the component and on the heat treatment, the hardness values are in the range of 500 to 630 HV10. After route 1, the hardness is on a low level of about $520 \mathrm{HV} 10$ at all positions, with exception of position 1. Due to the smaller material volume, a faster cooling of this region results in a higher hardness near the thermocouple. Additionally, the thermocouple is closer to the surface than at positions 2 and 3. In the center regions, the hardness is nearly $520 \mathrm{HV} 10$. The differences between thermocouple and center region of the positions 2 and 3 are small. Route 2 shows a strongly inhomogeneous hardness distribution. Position 1 is on a lower level of 560 HV10 near the surface. In contrast, position 4 shows the highest value of the whole setup of 636 HV10.

Table 2. Average values of Vickers hardness (HV10) of the component, measured at different positions (near thermocouple, center of component) after heat treatment via the described routes

\begin{tabular}{|l|l|c|c|c|c|c|}
\hline & & Position 1 & Position 2 & Position 3 & Position 4 & Position 5 \\
\hline Route 1 & Thermocouple & 591 & 528 & 520 & & \\
\hline & Center & 519 & 525 & 527 & 526 & 511 \\
\hline Route 2 & Thermocouple & 560 & 601 & 571 & & \\
\hline & Center & 563 & 593 & 548 & 636 & 589 \\
\hline
\end{tabular}

\section{Summary}

The experimental and numerical investigations show that two different Q\&P processes result in different temperature distributions within a forged component. However, in both cases the cooling rate was sufficient to develop a predominantly martensitic matrix with about 10 vol.- $\%$ of retained austenite, and with different martensite morphologies. During water quenching, the surface is more strongly cooled than the core. Hence, partitioning can be achieved by reheating from the core. The Q\&P process at the surface corresponds to a two-step heat treatment for the water cooling strategy and a single-step strategy at the core. Thus, two different martensite morphologies are formed in the component. A similar behavior was observed for the furnace cooling. Due to the slower cooling, the martensite needles are coarser. For a complete material and technology characterization, more investigations about the formation kinetic of martensite needles depending on the austenite grain size and influence of grain boundaries as well as the mechanical properties are future topics. 
Furthermore, D-TTT diagrams have to be determined from experimental cooling curves, representative for different points in the component. A detailed modelling of the material behavior and implementation into a commercial FE tool is possible. To shorten and model the complex process chain, the microstructural evolution has to be considered during forming as well as during the Q\&P treatment. Thermo-mechanical and thermo-physical parameters are required as well as the latent heat associated with the martensitic phase transformation.

\section{Acknowledgment}

This paper includes results achieved under projects LO1502 RoRTI and LO1412 DEWEMAT financed by the Ministry of Education, Youth and Sports (MEYS) of the Czech Republic.

\section{References}

[1] D.V. Edmonds, K. He, F.C. Rizzo, B.C. De Cooman, D.K. Matlock, J.G. Speer, Quenching and partitioning martensite - A novel steel heat treatment, Materials Science \& Engineering A $438-440$ (2006) 25-34.

[2] H. Jirková, L. Kučerová, B. Mašek, Effect of Quenching and Partitioning Temperatures in the Q-P Process on the Properties of AHSS with Various Amounts of Manganese and Silicon, Materials Science Forum 706-709 (2012) 2734-2739.

[3] B. Mašek, H. Jirková, D. Hauserová, L. Kučerová, D. Klaubeová, The Effect of Mn and Si on the Properties of Advanced High Strength Steels Processed by Quenching and Partitioning, Materials Science Forum 654-656 (2010) 94-97.

[4] E. J. Seo, L. Cho, Y. Estrin, B. C. De Cooman, Microstructure-mechanical properties relationships for quenching and partitioning processed steel, Acta Materialia 113 (2016) 124-139.

[5] J. G. Speer, F. C. Rizzo Assunção, D. K. Matlock, D. V. Edmonds, The Quenching and Partitioning Process: Background and Recent Progress, Materials Research 8, 4 (2005) 417-423.

[6] Y. Toji, G. Miyamoto, D. Raabe, Carbon partitioning during quenching and partitioning heat treatment accompanied by carbide precipitation, Acta Materialia 86 (2015) 137-147.

[7] S. Yana, X. Liu, W. J. Liu, T. Liang, B. Zhang, L. Liu, Y. Zhao, Comparative study on microstructure and mechanical properties of a C-Mn-Si steel treated by quenching and partitioning (Q \& P) processes after a full and intercritical austenitization, Materials Science \& Engineering A 684 (2017) 261-269.

[8] M. Wendler, C. Ullrich, M. Hauser, L. Krüger, O. Volkova, A. Weiß, J. Mola, Quenching and partitioning processing of fully austenitic stainless steels, Acta Mat. 133 (2017) 346-355.

[9] L. R. Villega, F. Lemoine, S. Tanguy, G. Castanet, O. Caballina, Direct numerical simulation of the impact of a droplet onto a hot surface above the Leidenfrost temperature, International Journal of Heat and Mass Transfer 104 (2017) 1090-1109.

[10]R. Jeschar, L. Maibücher, Experimentelle Untersuchung des Wärmeübergangs bei der Verdampfungskühlung im Sprühnebel, Forschungsbericht TU Clausthal, 2001. 